\title{
FACTOR VIII IN VON WILLEBRAND'S DISEASE
}

\author{
J. Foster Irwin, Ph.D.
}

The hemostatic problems encountered in von Willebrand's disease (VWD) appear to be corrected by factor VIII, one of the essential constituents of the blood coagulation system. Similarly, the bleeding problems encountered in classic hemophilia also are corrected by factor VIII. The clinical and laboratory observations suggest that these two diseases are very different, yet the genesis of both appears to result from absent or non-functional factor VIII. Our understanding of factor VIII and its relationship to VWD and classic hemophilia is an area of exciting research, and the apparent discrepancies which have been encountered are being resolved.

The important clinical observations and manifestations of VWD have been reviewed by Mammen in the previous article [81] and only briefly will be summarized here as they pertain to the level of factor VIII in VWD and in hemophilia. The defect in hemophilia appears to be a plasmatic defect. Although the defect in VWD gives the impression of being a capillary or platelet disorder, it now appears to be a plasmatic defect. In classical hemophilia the severity of the bleeding problem is related to the level of factor VIII activity in plasma; this level tends to remain fairly constant throughout life. Whereas factor VIII activity is absent or markedly suppressed, factor VIII levels detectable by immunologic procedures are normal. Bleeding problems can be corrected by the administration of antihemophilic factor (AHF) concentrates derived from normal plasma but not from serum. VWD on the other hand, appears to be more complex. VWD is characterized by depressed levels of both factor VIII activity and immunologically detectable factor VIII. Seldom are factor VIII levels as low as in hemophilia and seldom does the factor VIII level remain constant throughout life. The coagulopathy can be corrected in part or entirely by infusions of AHF fractions derived from hemophilic plasma and serum, as well as from normal plasma and serum [15, $19,26,94]$. In fact, infusion of normal and hemophilic plasma or serum appears to stimulate the production of factor VIII procoagulant activity above the levels expected; the converse infusion of normal or VWD plasma or serum into hemophiliacs does not overstimulate factor VIII procoagulant levels [31]. The variations encountered in hemophilia and VWD are often perplexing, but these same anomalies give more insight into the biochemistry of factor VIII and its relationship to these diseases.

Department of Physiology, Wayne State University School of Medicine, Detroit, Mich.

Seminars in Thrombosis and Hemostasis 2: 2 (October), 1975. 
In this paper the central role which factor VIII plays in von Willebrand's disease will be examined. Furthermore, the various functions which factor VIII appears to play as it relates to VWD and hemophilia, the characterization of factor VIII in selected biochemical and immunologic terms, and the presumed anomaly in the patterns of inheritance of factor VIII in both diseases will be reviewed.

From the data of many experiments we hope to leave the impression that factor VIII, as we have known it, now may be a large complex of at least two molecules. One molecule is of high molecular weight and its absence is responsible for von Willebrand's disease. The other molecule is of low molecular weight and appears to be associated by non-covalent bonds to the larger molecule; its presence is responsible for normal procoagulant activity.

\section{FUNCTIONS OF FACTOR VIII}

Factor VIII has been assigned a number of functions and/or activities, the ability to correct hemophilia and von Willebrand's disease being two of these activities. It should be emphasized that functions assigned to factor VIII have been based upon the presumption that the activity used to correct various defects is attributable to factor VIII and not to some contaminant in the correcting preparation. The assignment of these activities to factor VIII has been confusing at times; in this regard, the complexity of nomenclature can be appreciated by examining a recent report on factor VIII nomenclature by the International Society on Thrombosis and Haemostasis [42]. The functions and activities of factor VIII which will be discussed in this paper are as follows: VIII ${ }_{\text {coag }}$, the ability to correct the procoagulant defect in hemophilia and VWD plasmas; VIII $\mathrm{VWF}$, the von Willebrand's factor, an activity which is capable of correcting the bleeding abnormalities in von Willebrand's disease; VIII $_{\mathrm{ag}}$, the factor VIII associated antigen. a protein which is detected immunologically using heterologous antisera prepared against purified factor VIII preparations; VIII $_{\text {neut }}$, the factor VIII neutralization substance, a protein which neutralizes homologous antibodies specifically directed against VIII $_{\text {coag activity; }} \mathrm{VIII}_{\text {rist }}$, the ristocetin aggregating factor activity, an activity present in factor VIII preparations which permits the antibiotic ristocetin to aggregate human platelet-rich plasma; and $\mathrm{VIII}_{\mathrm{PAF}}$, the platelet aggregating factor present in bovine and porcine preparations of factor VIII and in neuraminidase-treated human preparations of factor VIII which induces the aggregation of human platelet rich plasma. A summary of these factor VIII activities detected in most normal, hemophilia and VWD plasma and serum can be found in Table 1.

\section{The Factor VIII Procoagulant Activity, VIII coag}

The observations of numerous investigators have established that factor VIII activity levels are moderately to severely depressed in VWD and classic hemophilia, when measured in coagulation tests such as the partial thromboplastin time test (PTT) and the prothrombin consumption test (PCT). This abnormal coagulation activity is corrected by normal plasma and fractions derived from it [2] but not by aged plasma or normal serum $[43,69,97]$. Addition of crude or presumably 
TABLE 1. Factor VIII Activities in Normal, Hemophilia and VWD Plasma and Serum

\begin{tabular}{|c|c|c|c|c|c|c|}
\hline \multirow[b]{2}{*}{$\begin{array}{l}\text { Source } \\
\text { Material }\end{array}$} & \multicolumn{6}{|c|}{ Normal Levels of Factor VIII Activity } \\
\hline & $V I I I_{\text {coag }}$ & $V I I I_{a g}$ & $V I I I_{V W F}$ & $V I I I_{\text {neut }}$ & $V I I I_{\text {rist }}$ & $V I I I_{P A F^{*}}$ \\
\hline \multicolumn{7}{|l|}{ Normal } \\
\hline Plasma & + & + & + & + & + & + \\
\hline Serum & - & + & + & + & + & + \\
\hline \multicolumn{7}{|l|}{ Hemophilia } \\
\hline $\mathrm{CRM}^{-}$Plasma & - & + & + & - & + & + \\
\hline Serum & - & + & + & - & + & + \\
\hline $\mathrm{CRM}^{+}$Plasma & - & + & + & + & + & $(+)$ \\
\hline Serum & - & + & + & + & + & $(+)$ \\
\hline \multicolumn{7}{|l|}{ von Willebrand } \\
\hline Plasma & - & - & - & - & - & - \\
\hline Serum & - & - & - & - & - & - \\
\hline
\end{tabular}

*VIIIPAF refers to the ability of bovine and porcine factor VIII or neuraminidase- treated human VIII fractions to aggregate human platelet rich plasma. VIIIPAF is presumably normal in $\mathrm{CRM}^{+}$hemophilic individuals.

purified preparations of normal factor VIII to VWD and hemophilia plasmas normalize the PTT and PCT tests. Infusion of normal AHF fractions into VWD patients [94] and hemophiliacs [99] stabilizes the bleeding episodes of these patients and corrects the coagulation screening tests of their plasmas.

\section{The Factor VIII Associated Antigen, VIII ag}

As soon as hemophilia was discovered, attempts were made to correct the coagulopathy using normal plasma fractions. This was soon followed by attempts to purify factor VIII from plasma. As the purity of the preparations of factor VIII improved, antisera were prepared in laboratory animals against these purified factor VIII preparations. The general criteria of purity of factor VIII were based upon increased specific activity of the preparations' procoagulant activity, VIII coag. Heterologous antisera prepared against purified factor VIII fractions were capable of immunoprecipitation reactions, such as immunodiffusion, immunoelectrophoresis, and immunoelectrodiffusion, when reacted against normal plasma or serum and factor VIII preparations derived from normal plasma or serum. These heterologous antisera were also capable of neutralizing the VIII coag $_{\text {of normal }}$ plasma. Originally, antisera were thought to be specifically against VIII $_{\text {coag. }}$. However, when normal levels of VIII ${ }_{\mathrm{ag}}$ were detectable in normal serum and in all hemophilic plasmas $[60,91,109,123]$, both of which have moderately to severely depressed levels of VIII $_{\text {coag }}$, a distinction between factor VIII procoagulant activity and immunologically detectable factor VIII had to be made. Thus the term factor VIII associated antigen, VIII ${ }_{a g}$, arose to describe the protein in which VIII $_{\text {coag }}$ resides or with which $\mathrm{VIII}_{\text {coag }}$ is associated and which can be detected using heierologous antisera. The level of VIII ${ }_{\mathrm{ag}}$ in almost all cases of VWD is depressed and appears to be correlated with the depressed levels of VIII $\operatorname{coag}_{2}[60,123]$. This is in contrast to the depressed VIII ${ }_{\text {coag }}$ levels and normal VIII ${ }_{\mathrm{ag}}$ levels encountered 
in mosi cases of hemophilia. The relative ratio of $\mathrm{VIII}_{\text {coag }}$ to $\mathrm{VIII}_{\mathrm{ag}}$ in VWD individuals is approximately one, a value identical to that in normal individuals. On the other hand, hemophiliacs have a value considerably less than one. Hemophilic carriers have a value which is intermediate $[16,122]$. These observations have led to the belief that VWD individuals do not synthesize an immunologically detectable factor VIII molecule, whereas hemophiliacs do synthesize an immunologically detectable but nonfunctional factor VIII molecule $[25,61]$.

\section{The von Willebrand Factor Activity, VIIIVWF}

Von Willebrand's disease is characterized by an apparent platelet disorder. In most cases, a prolonged bleeding time is encountered, platelet adhesiveness to surfaces is decreased, and the $\mathrm{VIII}_{\text {coag }}$ and $\mathrm{VIII}_{\mathrm{ag}}$ levels are depressed [123]. In addition, and perhaps one of the most definitive criteria for diagnosing VWD [47, 97], the apparent biologic half-life of $\mathrm{VIII}_{\text {coag }}$ is prolonged following infusion of AHF concentrates compared to what would be expected and what is observed in hemophiliacs $[19,94]$. Whereas there is an apparent super-response or overstimulation in the detectable $\mathrm{VIII}_{\text {coag }}$ levels of VWD individuals, the $\mathrm{VIII}_{\text {ag }}$ levels are not stimulated to the same extent. Factor VIII preparations derived from normal plasma or serum correct the abnormal clinical and laboratory parameters seen in VWD. Bleeding times and platelet adhesiveness are corrected and platelet aggregation induced by the antibiotic ristocetin [58] is normalized. Interestingly, factor VIII-like preparations derived from hemophilic plasma and serum and devoid of procoagulant activity can also correct the manifestations of VWD [97]. The conclusion derived from these observations and those from experiments using strains of dogs and pigs which have VWD, is that VWD plasma, in contrast to normal and hemophilic plasma and serum, lacks a factor, the von Willebrand factor or $\mathrm{VIII}_{\mathrm{VWF}}$, necessary for the normal expression of both platelet function and coagulation function. VIII $_{\mathrm{VWF}}$ activity presumably resides with the factor VIII molecule, specifically the factor VIII associated antigen, VIII $_{\mathrm{ag}}$.

\section{The Factor VIII Antibody Neutralization Substance, VIII neut}

This function is not ordinarily accepted as a separate activity; however, for the purposes of this review it will be used to give clarity to the different factor VII functions and activities. In a number of hemophiliacs there has developed an antibody against factor VIII as a result of receiving infusions of factor VIII concentrates used to stabilize their coagulopathy. In addition, spontaneous inhibitors against factor VIII develop for unknown reasons in some persons, both men and women. These persons having a spontaneous antibody inhibitor have hemophilia in the truest sense of the disease and are no different from the congenital hemophiliac in terms of the clinical observations; only the origin or cause of the hemophilia and the management of the patient appear to be different. These antibodies are called homologous antibodies, as opposed to heterologous antibodies derived from a different species. Homologous antibodies inactivate

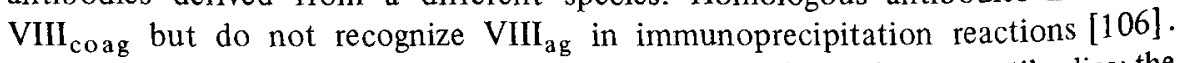
These observations contrast with those obtained with heterologous antibodies; the latter not only destroy VIII $_{\text {coag }}$, but also undergo immunoprecipitation reactions 
with VIII $_{\mathrm{ag}}$ in normal plasma and serum. Thus, normal plasma and factor VIII fractions derived from normal plasma contain a substance capable of neutralizing or inactivating homologous inhibitors, thus the term VIII neut. Furthermore, this neutralizing activity persists in normal serum even though VIII ${ }_{\text {coag }}$ has been lost [1]. Whereas normal plasma has normal VIII neut levels, most hemophiliacs have moderately to severely depressed levels of VIII $_{\text {neut }}$, depending upon the severity of the disease. Confusion has arisen regarding the hemophiliac, however, in

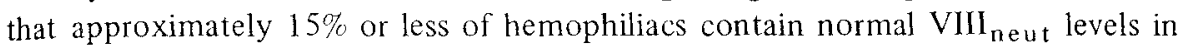
spite of the fact that they have markedly depressed VIII $_{\text {co ag }}$ levels $[35,37,61,73$, 90]; this discrepancy appears to be related to a nonfunctional form of VIII coag. VIII $_{\text {neut }}$ levels are almost always moderately depressed in VWD in relation to the level of VIII coag $[73,90]$. Except for those $15 \%$ of hemophiliacs who have normal VIII $_{\text {neut }}$ levels, there appears to be a good correlation between VIII neut $_{\text {and }}$ VIII $_{\text {coag activities in normal, hemophilia and VWD individuals. In fact, VIII }}$ eut is believed to be identical to VIII $_{\mathrm{coag}}$.

\section{The Ristocetin Aggregating Factor, VIII rist}

The antibiotic ristocetin had been used in patients to treat gram-positive bacterial infections but was eventually removed from clinical usage presumably because of its platelet aggregating activity. USFDA subsequently has approved its limited usage for investigative diagnostic purposes. It was found that normal platelet rich plasma (PRP) would aggreagate when ristocetin was added to the in vitro test system but that ristocetin-induced aggregation of VWD PRP did not occur or was impaired $[58,119,120]$. Although recent studies have shown that all patients who have VWD have impaired ristocetin-induced aggregation [95], other studies have shown that some VWD individuals who have questionable platelet adhesiveness may have normal ristocetin-induced platelet aggregation $[4,59]$. The impaired ristocetin-induced platelet aggregation in VWD PRP can be corrected by the addition of normal and hemophilic plasma and serum as well as factor VIII-like preparations derived from plasma or serum. Thus, VWD plasma lacks an activity, VIII $_{\text {rist }}$, which is essential for normal platelet aggregating function; this activity is associated with the factor VIII molecule of normal and hemophilic individuals [120]. The ristocetin-induced aggregating factor is believed to be the same as the von Willebrand's Factor. Both VIII ${ }_{\text {rist }}$ and VIIIVWF levels correlate well with

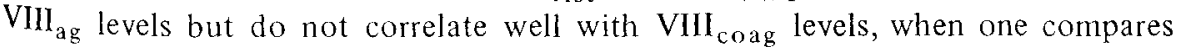
normal, hemophilic and VWD individuals.

\section{The Platelet Aggregating Factor, VIIIPAF}

Normal bovine and porcine factor VIII from plasma or serum $[36,38,46,77]$, but not from porcine VWD plasma [33], aggregates human PRP. VIII PAF is associated with galactose carbohydrate side-chains, for VIII PAF is lost by pretreatment with galactose oxidase [125]. Normal and hemophilic but not VWD

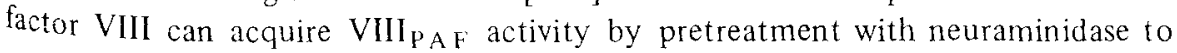
remove sialic acid, thereby exposing galactosyl residues [124]. Pretreatment of human VIII with neuraminidase and galactose oxidase does not produce VIII PAF $_{\text {F }}$ activity [125]. VIII PAF correlates with VIII VWF [33] and is similar to VIII ${ }_{\text {ag }}$ if not identical. 


\section{CHARACTERIZATION OF FACTOR VIII}

\section{Biochemical Characterization}

Factor VIII is intimately associated with the intrinsic pathway of blood coagulation where it is essential for the conversion of prothrombin to thrombin, a phenomenon which is impaired in hemophilia A [27]. The virtual absence of antihemophilic factor activity from normal serum [43,69] and the destruction of it by thrombin [70] indicates that factor VIII procoagulant activity is destroyed during clotting. The biochemistry of factor VIII and other blood clotting constituents in hemostasis has been reviewed numerous times, most recently by Davie and Fujikawa [32]; the physiology of factor VIII has been reviewed recently by Barrow and Graham [10]. In blood coagulation, factor VIII acts as a cofactor $[56,96]$, assisting factor IXa in the conversion of factor $\mathrm{X}$ to $\mathrm{Xa}$ in the presence of phospholipids and calcium ions. Factor VIII does not act as an enzyme as originally had been thought, in spite of the fact that low levels of thrombin may enhance the biological activity of it $[18,101]$. The level of factor VIII in human plasma appears to be $10 \mu \mathrm{g} / \mathrm{ml}$ or less [82], although earlier estimates suggested that it may be $20-50 \mu \mathrm{g} / \mathrm{ml}[28,100]$.

The sites of synthesis of factor VIII have not been definitively established although spleen, liver, kidney and leukocytes have been implicated; Barrow and Graham [10] and Jaffe [66] have compiled and summarized this information. Recent evidence suggests that the endothelial cell may be implicated since immunologically detectable factor VIII could be found on endothelial cells of a variety of tissues using immunofluorescent technics [22, 34, 63]. In addition, immunologically detectable factor VIII having VIII $\mathrm{VWF}$ activity appears to be synthesized in and relased from cultured human endothelial cells $[66,67,681$. Determination of sites of synthesis of a factor VIII molecule may be even more complicated in view of recent findings that the factor VIII molecule may consist of two molecular species, one associated with VIII coag $_{\text {and one associated with }}$ VIII $_{\mathrm{VWF}}$.

Factor VIII has been isolated to various degrees of purity by a number of procedures. A summary of earlier methodology for isolating factor VIII has been compiled by Mammen [80]. Isoelectric precipitation, salting and organic solvent precipitation, and cryoprecipitation procedures were used in the earliest attempts to isolate crude concentrates of factor VIII; these methods, particularly ethanol precipitation and cryoprecipitation, still yield useful source material for clinical usage. More recently, combinations of the above technics with ion exchange chromatography (separation on the basis of molecular charge), gel filtration (separation on the basis of molecular size) and affinity chromatography (separation on the basis of factor VIII affinity to immobile ligands or immobile antibodies) have resulted in purified factor VIII preparations capable of being characterized.

Fibrinogen is a major contaminant of crude factor VIII preparations; indeed there appears to be a close affinity or association of these two molecules for one another. Unfortunately, although fibrinogen is a contaminant of factor VIII preparations, fibrinogen also appears to be a stabilizer of factor VIII procoagulant activity. Separation of fibrinogen from factor VIII not only results in decreased 


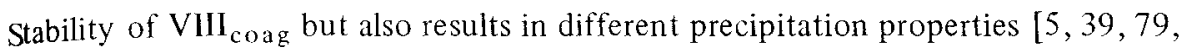
$92,111]$. This marked lability has made isolation and characterization of the factor VIII molecule difficult.

The molecular weight of human and animal preparations of factor VII has been reported to be from under 200,000 daltons to over $2,000,000$ daltons. Some earlier sedimentation coefficients of approximately 6.5 Svedberg units have been reported [78, 108]. These would be consistent with a molecular weight of 200,000 or somewhat less and are consistent with the molecular weight of 180,000 determined by electron irradiation [3].

On the other hand, $\mathrm{S}_{20, \mathrm{w}}$ values of 12 to 19 for human, bovine, porcine and canine preparations of partially purified AHF [51] suggest that factor VIII may be a much larger molecule consistent with a molecular weight of about $1,000,000$ or more. More recently, gel filtration studies in $2.6 \%$ agarose as a means of estimating molecular weight have strengthened the belief that factor VIII is a glycoprotein with a molecular weight of $1-3$ million $[50,71,75,76,82,83,98,104,105,118]$. Some of the discrepancies in molecular weight estimations were originally thought to be due in part to aggregation of factor VIII which might arise during purification $[51,78,82]$. This is probably not likely, however, since highly purified factor VIII behaves as a high molecular weight substance in the presence of dispersing agents and as a substance with molecular weight 100,000-200,000 only after reduction of the disulfide bonds of the purified factor VIII $[75,76,82,84$, $104,105]$. Furthermore, even factor VIII from plasma has a molecular weight of 1-3 million, when passed over filtration columns [118]. Some of the discrepancies in molecular weight encountered by investigators may thus be due to the existence of two different forms of factor VIII in plasma with grossly different molecular weights. Weiss and Kochwa [117] showed that in human citrated plasma two regions of VIII coag activity were detected following ultracentrifugation in a 10-40\% sucrose gradient, a main, fast sedimenting activity in the region of aM-macroglobulin and a minor, slow sedimenting activity in the region of

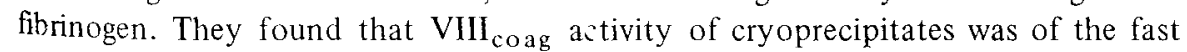
type, whereas the supernatant factor VIII $_{\text {coag }}$ activity remaining after cryoprecipitation was of the slow type; it was noted that the fast type did not contain any fibrinogen which might have competed with factor VIII. Furthermore, they suggested that the heavier or faster form converted to the slower form when the former was centrifuged in a media of high salt concentration. Factor VIII $_{\text {coag }}$ activity having a molecular weight of approximately 25,000 has also been found in kidney extracts $[6,8]$ and in plasma of von Willebrand's patients following infusion of AHF concentrates $[20,21]$. Although these VIII $_{\text {coag activities have not been }}$

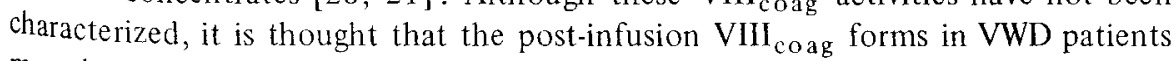
may be different than VIII coag from normal individuals [17]. Finally, low

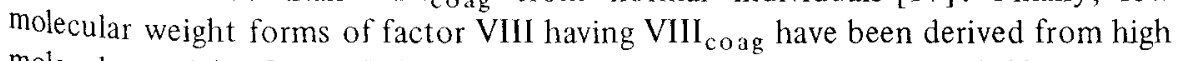
molecular weight factor VIII when the latter was subjected to gel filtration or sucrose gradient ultracentrifugation in the presence of high ionic strength salt solutions or $0.25 \mathrm{M} \mathrm{CaCl}_{2}[98,110,117,118]$.

Although purification of factor VIII has been tedious, sufficiently pure preparations have been obtained to characterize it. By reducing purified factor VIII with 2-mercaptoethanol or some other reducing agent in the presence of sodium dodecyl sulfate, and running these preparations on polyacrylamide gel electro- 
phoresis, both the number of different subunits and the molecular weight of these subunits can be determined. From a number of investigations, purified factor VIII having both $\mathrm{VIII}_{\text {coag }}$ and $\mathrm{VIII}_{\mathrm{VWF}}$ or $\mathrm{VIII}_{\mathrm{PAF}}$ activities, depending upon source material, can be shown to consist of a number of apparently identical subunits held together by disulfide bonds $[14,48,50,75,76,82,83,84,104,105]$. These monomers range in size from 25,000 to 240,000 , with the most prevalent finding in the region of 100,000 to 200,000 . It is important to note that these subunits could be detected on polyacrylamide disc gels only after reduction of the disulfide bonds holding the subunits together; no small molecular weight subunits could be detected without reduction. By way of comparison, there are no detectable differences between the factor VIII molecule derived from normal individuals and that derived from hemophiliacs $[14,52,84,105]$.

Recently, however, Van Mourik and associates [112] were able to dissociate purified human factor VIII at low ionic strength in the absence of reducing agents into a slow- and a fast-moving component, both of which had different immunologic characteristics. Also, the dissociation and the subsequent separation of low molecular weight factor VIII procoagulant activity from the high molecular weight protein in the presence of $1 \mathrm{M} \mathrm{NaCl}$ or $0.25 \mathrm{M} \mathrm{CaCl}_{2}$ has been reported [ 98 $110,117,118]$. These components can be recombined in the absence of calcium to

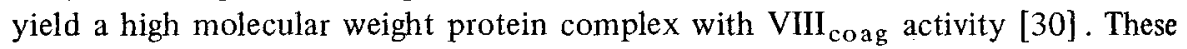
experiments were done in the absence of reducing agents and suggest that factor VIII is a complex consisting of a high molecular weight (HMW) protein of about $2,000,000$ and a low molecular weight (LMW) protein held to the carrier by non-covalent bonds. The large component has no $\mathrm{VIII}_{\text {coag, }}$ whereas the small component does have $\mathrm{VIII}_{\text {coag. }}$. The LMW protein is estimated to have a molecular weight of between 25,000 and 300,000 based upon its filtration and ultracentrifugation properties. Whereas the LMW component is detectable by its procoagulant activity, little protein material has been found associated with this activity. This is an important observation, for a number of investigators believe these results to be artifacts $[32,49,84]$. Some point out that the $\mathrm{LMW} \mathrm{VIII}_{\text {coag }}$ could not be detected when highly purified factor VIII is used. It appears that the detection of

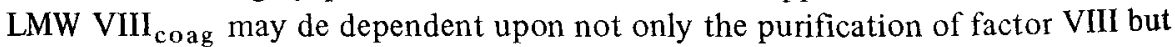
also upon whether the starting material was cryoprecipitate [114].

\section{Immunologic Characterization}

1. Homologous Antibodies. Immunologic technics have played a major role in the elucidation of factor VIII structure and function. The use of homologous antibodies against VIII $_{\text {coag, }}$, i.e. antibodies which develop in hemophilic patients or which develop spontaneously in normal individuals, have the capacity of inactiv-

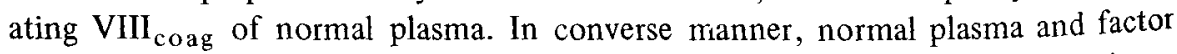
VIII preparations have the ability to neutralize the activity of homologous antisera, thus the term "VIII ${ }_{\text {neut }}$ activity." These homologous antibodies, however, do not appear to undergo immunoprecipitation reactions with factor VIII [106], more specifically, the VIII $_{\mathrm{ag}}$ substance of normal plasma; thus, they do not form precipitin lines upon immunoelectrophoresis or immunodiffusion. In addition, VIII $_{V W F}$ and VIII $_{\text {rist }}$ are not impaired in the presence of human antibody [23, 
87]. When homologous antisera are incubated with normal and VWD plasma, normal plasma neutralizes the inhibitor, whereas VWD plasma either does not neutralize the inhibitor or neutralizes the inhibitor in proportion to it's VIII coag $_{\text {a }}$ level. Thus, normal plasma has VIII $_{n e u t}$ and VWD plasma does not $[35,61,73$, 90]. Similar experiments indicate that most hemophiliacs, like VWD individuals, either lack VIII $_{\text {neut }}$ or have low levels of VIII $_{\text {neut }}$ in relation to the level of VIII $_{\text {coag }}[1,35,61,73,90]$. It can be shown, however, that a small proportion of hemophiliacs, approximately $6-15 \%$, contain a cross-reacting material (CRM) capable of neutralizing homologous antibodies $[35,37,41,61,73,90]$. VIII neut material in hemophiliacs is believed to be a nonfunctional form of factor VIII which lacks procoagulant activity; they are designated $\mathrm{CRM}^{+}$or hemophilia $\mathrm{A}^{+}$. This is in contrast to the majority of hemophiliacs who apparently do not synthesize any type of factor VIII and, therefore, have no cross-reacting material; these are designated CRM or hemophilia $\mathrm{A}^{-}$. The VIII $_{\text {neut }}$ component in hemophilia $\mathrm{A}^{+}$individuals appears to be similar to that in normal plasma, in that both are destroyed by heating at $56^{\circ} \mathrm{C}$ for 30 minutes $[62,88]$. Stored normal plasma retains significant $\mathrm{VIII}_{\text {neut }}$, even though $\mathrm{VIII}_{\text {coag }}$ has deteriorated.

2. Heterologous Antibodies. When purified factor VIII is used to produce antibodies in animals, the heterologous antisera not only neutralize VIII coag of normal plasma but also precipitate antigenic material from normal plasma and destroy VIIIVWF [86]. Barrow and Graham [10] have summarized the results of experiments published through 1972 which have used heterologous antisera to study factor VIII in normal, hemophilic and VWD individuals. The conclusion derived from these experiments is that the great majority, if not all, hemophiliacs contain antigenic material capable of cross-reacting with antisera prepared against factor VIII in various states of purity. Furthermore, the VIII $_{\mathrm{ag}}$ synthesized by hemophiliacs appears to be immunologically identical to VIII $_{\mathrm{ag}}$ synthesized by normal individuals [24]. The only exception to this conclusion was reported by Gralnick and associates [44], who found only 8 of 55 hemophilic plasmas which neutralized goat antibody to partially purified normal factor VIII. The results of Zimmerman et al [123] are of particular importance. Using sensitive immunological procedures, they were the first to show that all hemophilic plasmas have antigenic material capable of cross-reacting with rabbit antisera and that this $\mathrm{VIII}_{\mathrm{ag}}$ was comparable in amount to that in normal plasma. Furthermore, their results also prove that VWD individuals have non-existent or markedly depressed levels of VIII $_{a g}$. These results suggest that normal individuals and hemophiliacs synthesize a substance, VIII $_{\mathrm{ag}}$, which VWD individuals do not; this plasma substance appears to be necessary for normal platelet function.

\section{Comparison of Structure and Function}

The detection of VIII $_{\text {ag }}$ in normal and hemophilic plasma but not in VWD plasma [123] suggested that VIII $_{a g}$ was necessary for the normal hemostatic mechanisms to operate in VWD. Indeed, addition of normal AHF and hemophilic antigenic material to VWD plasma does correct the defective adhesion of VWD platelets to glass $[23,25]$ and the defective ristocetin-induced platelet aggregation of VWD platelet rich plasma $[58,119,120]$. 
Purified high molecular weight preparations of factor VIII elute in the void volume of $2-6 \%$ agarose columns, a procedure which separates proteins on the basis of their molecular size. Using various types of assay procedures, it has been demonstrated that purified factor VIII has all of the functional activities attributed to factor VIII in normal plasma and in AHF preparations: VIII $_{\text {coag }}$, VIII ag $_{\text {, }}$ VIII $_{\text {neut }}, \mathrm{VIII}_{\mathrm{VWF}}, \mathrm{VIII}_{\text {rist }}$ and $\mathrm{VIII}_{\mathrm{PAF}}$. The coincidence of these activities suggests identity of structure and function. If, however, factor VIII preparations are dissociated in $1 \mathrm{M} \mathrm{NaCl}$ or $0.25 \mathrm{M} \mathrm{CaCl}_{2}$ and then separated by filtration or ultracentrifugation in the presence of dissociating agents, two components are obtained, a high molecular weight (HMW) component of 1-2 million which lacks VIII $_{\text {coag, and a low molecular weight (LMW) component of } 100,000-300,000}$ which retains VIII $_{\text {coag }}$ but which is associated with little or no detectable protein $[98,110,117,118]$. The LMW component is inhibited by both human and rabbit antibodies which do not precipitate this material, whereas the HMW component precipitates rabbit antibodies but does not inhibit human antibodies $[98,103]$. VIII $\mathrm{VWF}, \mathrm{VIII}_{\text {rist }}$ and VIII $_{\mathrm{PAF}}$ appear to reside only with the HMW component and not with the LMW component $[13,46,115,120]$. Not only has dissociation of factor VIII into two components been possible using molecular sizing technics, but also separation of $\mathrm{VIII}_{\mathrm{ag}}, \mathrm{VIII}_{\mathrm{PAF}}$ and $\mathrm{VIII}_{\text {rist }}$ activities from VIII $_{\text {coag }}$ has been attained using ion exchange chromatography [13, 29, 46, 74]. Needless to say, more must be done to characterize the LMW component if questions regarding its origin and nature are to be answered.

Cooper and Wagner [30] not only dissociated purified normal factor VIII from human, bovine and canine plasmas into HMW and LMW components, but also recombined these components in the absence of calcium to yield a HMW substance

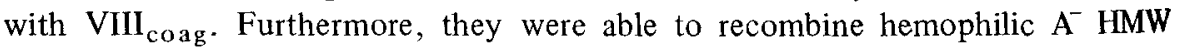
component with normal LMW component, but they were not able to recombine canine hemophilic HMW or human VWD HMW components with normal LMW components from their respective species. They suggest that human hemophilia $A$ HMW component has a functional "receptor" capable of accepting LMW component, whereas the canine hemophilia and human VWD HMW components do not.

Low molecular weight forms of factor VIII are also produced by thrombin. The destruction of $\mathrm{VIII}_{\text {coag }}$ by thrombin has long been known [70] in spite of the fact that trace levels of thrombin appear to enhance the biological activity of factor VIII $[18,101]$. Treatment of plasma with thrombin converted a rapidly sedimenting form of $\mathrm{VIII}_{\text {coag }}$ in sucrose density ultracentrifugation to a slower sedimenting form of VIII coag [117]. Recalcification of normal human cryoprecipitate produces a HMW form of VIII which neutralizes rabbit and human anti-factor VIII but which has no VIII $_{\text {coag }}$, and a LMW form of VIII coag which is inhibited by rabbit and human anti-factor VIII [40]. Although normal serum contained factor VIII components similar to those found in recalcified cryoprecipitates, low level thrombin alone produced HMW and LMW forms, both of which had VIII $\mathrm{V}_{\text {coag. }}$. Even though VIII $_{\text {coag }}$ is lost when thrombin treatment or coagulation occurs, antigens identifiable by human or rabbit antibodies $[1,115,116,123]$ and VIIIVWF activity are preserved. 
Finally, the dissociation of purified factor VIII in to two components following dialysis in low ionic strength buffers $[112,113]$ suggests a possible separation of structure and function. These components had different precipitation properties on crossed immunoelectrophoresis. In addition, they both cross-reacted with heterologous antisera against factor VIII in immunodiffusion studies but demonstrated a reaction of non-identity between each other. Further experiments must be done to clarify the importance of these observations and to determine whether or not these two components possess any factor VIII functional activities.

Separation of factor VIII activities by chromatographic procedures and other experimental procedures $[57,87,121]$ suggest that VIII $_{\text {coag }}$ resides on a protein other than VIII $_{a g}$ in spite of the observation that VIII coag and VIII ag are associated in a one-to-one relationship in normal and in VWD individuals. On the other hand, the detection of some VWD patients with normal VIII coag $_{\text {and low }}$

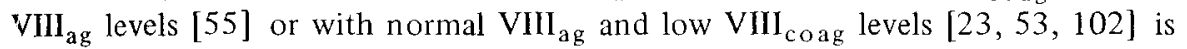
consistent with a two-protein concept for VIII $_{\text {coag }}$ and $\mathrm{VIII}_{\mathrm{ag}}$. This concept is supported by the fact that homologous antibodies neutralize VIII coag $_{\text {of normal }}$ plasma but do not precipitate $\mathrm{VIII}_{\mathrm{ag}}$, an observation which suggests a separation of VIII $_{\text {coag }}$ and VIII $_{\mathrm{ag}}$ antigenic determinants. In contrast, heterologous antibodies both destroy VIII $_{\text {coag }}$ and precipitate VIII $_{a g}$. This suggests identity of VIII coag and $\mathrm{VIII}_{\mathrm{ag}}$ antigenic determinants or very close proximity of these antigenic determinants. This apparent discrepancy between the properties of homologous and heterologous antibodies might be explained by noting that homologous antibodies

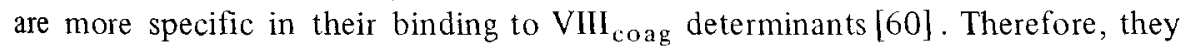
would destroy VIII $_{\text {coag }}$ but would not precipitate VIII $_{\text {ag }}$, because they do not form a stable complex with the factor VIII molecule as a whole. Heterologous antibodies, on the other hand, are less specific in their binding [60] and would form a stable complex with the entire factor VIII molecule, thereby precipitating

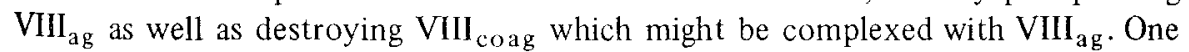
wonders whether or not heterologous antibodies could be produced specifically against $\mathrm{VIII}_{\mathrm{ag}}$ using the high molecular weight component of factor VIII produced by dissociating purified factor VIII in $1 \mathrm{M} \mathrm{NaCl}$ or $0.25 \mathrm{M} \mathrm{CaCl}_{2}$ ? Better yet, would heterologous antibodies specific for VIII $_{\mathrm{ag}}$ be produced using the VIII $_{\mathrm{ag}}$ antigen from hemophilia $\mathrm{A}^{-}$individuals who had also developed an inhibitor to $\mathrm{VIII}_{\mathrm{coag}}$ ? This latter challenging antigen would be free of all traces of VIII coag and VIII neut In this regard the available evidence suggests that these neutralizing and precipitating properties of heterologous antisera can be separated $[57,60]$. It is interesting to note that Gralnick and co-workers [45] produced a rabbit antibody against purified factor VIII in which VIII $_{\text {coag }}$ had decayed. The resultant antibody induced a VWD state and precipitated protein from normal plasma but would not neutralize VIII coag.

There is little doubt that VIII coag and VIII $_{\text {neut }}$ functions reside with the same protein and in fact are identical. VIII ${ }_{\text {coag }}$ refers to a procoagulant activity; VIII $_{\text {neut }}$ refers to a specific protein which neutralizes the inhibitor capacity of homologous antisera directed against VIII $_{\text {coag. Homologous antisera neutralize }}$ VIII $_{\text {coag }}$ but do not recognize either VIII $_{\text {ag }}$ in normal or hemophilic plasma or the high molecular weight component after dissociation of purified factor VIII in high ionic strength solutions. In hemophilia $\mathrm{A}^{+}$individuals the term $\mathrm{VIII}_{\mathrm{neut}}$ also 
pertains to a molecule which has a nonfunctional form of VIII $_{\text {coag }}$; presumably nonfunctional VIII $_{\text {neut }}$ protein has lost its VIII $_{\text {coag activity as a result of an amino }}$ acid substitution at a site essential for $\mathrm{VIII}_{\text {coag }}$ activity.

The fact that VIII $_{\mathrm{ag}}, \mathrm{VIII}_{\mathrm{VWF}}, \mathrm{VIII}_{\text {rist }}$ and $\mathrm{VIII}_{\mathrm{PAF}}$ are associated with the same high molecular weight component on filtration in dissociating salts and are not separable on ion exchange chromatography suggests that each of these functional capacities resides on the same protein, i.e., VIII $_{a g}$. Generally, when VIII $_{\mathrm{ag}}$ is depressed in VWD patients, VIII $\mathrm{VWF}$ and $\mathrm{VIII}_{\text {rist }}$ also are depressed. Similarly, when VIII $_{\text {ag }}$ is depressed in VWD strains of pigs or dogs, VIII PAF and VIII $_{V W F}$ are depressed. The presumption is that in VWD the individual lacks VIII $_{a g}$ and, therefore, lacks von Willebrand factor. The fact that VIII ${ }_{\text {rist }}$, VIIIVWF and VIII $_{\text {PAF }}$ appear to be inseparable from VIII $_{\mathrm{ag}}$ does not prove identity with VIII $_{\text {ag }}$. Until evidence to the contrary, it is a presumption that these functional capacities are identical. Our concern for this point arises from the observation that there are some individuals who have von Willebrand's trait, yet have normal VIII $_{\mathrm{ag}}$ levels and normal or depressed levels of VIII $_{\text {coag }}[23,53,89,102]$. Presumably, these individuals lack $\mathrm{VIII}_{\mathrm{VWF}}$ capable of correcting bleeding times and platelet adhesiveness in spite of the fact that VIII $_{\text {ag levels were normal. Our concern could }}$ be unfounded for it is possible that von Willebrand's trait in these variants could arise from a non-functional form of VIII $_{\mathrm{ag}}$. The other possibility is that $\mathrm{VIII}_{\mathrm{ag}}$ and VIII $_{V W F}$ do not share the same antigenic determinants and may in fact be different from one another.

\section{Relationship of Albumin to Procoagulant Activity}

A number of interesting observations dealing with the relationship of albumin to factor VIII procoagulant activity have been reported. Succinylation of plasma yielded factor VIII-like activity of low molecular weight [7, 9] which had very similar characteristics to the low molecular weight factor VIII-like activity derived from leucine aminopeptidase preparations of kidney tissue $[6,8]$. Furthermore,

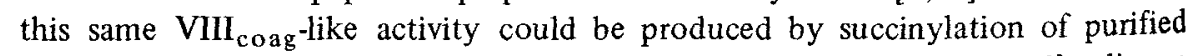
albumin derived from normal, hemophilia $\mathrm{A}$ and von Willebrand's disease plasmas [12]. Heterologous antisera prepared against purified albumin free of any VIII $_{\text {coag }}$ were capable of neutralizing VIII coag of normal plasma [11]. In addition, the factor VIII neutralizing capacity of this anti-albumin could be blocked by normal and hemophilic albumin but not by VWD albumin. Our understanding of the importance of this relationship of albumin to factor VII procoagulant activity is insufficient; it must await further clarification.

\section{GENETICS OF FACTOR VIII}

It is well known that factor VIII deficiency is an inheritable trait as it relates to both hemophilia A and von Willebrand's disease. What is generally not appreciated is that a number of environmental factors and drugs can also affect the level of

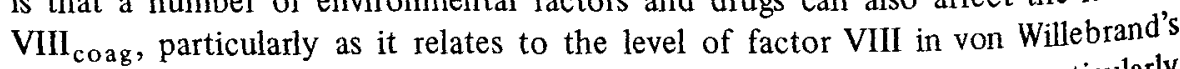
disease. Ingram has reviewed these parameters [64]. In brief, estrogens, particularly 
in the last trimester of pregnancy, hyperthyroidism and epinephrine infusion or those states which induce elevated plasma epinephrine levels, such as exercise, fright

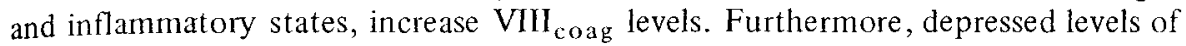

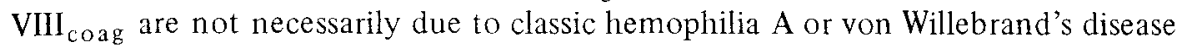
but may be due to the development of spontaneous inhibitors against VIII $_{\text {coag, a }}$ subject which has been reviewed recently [107]. The inheritance of factor VIII is confusing in that three distinctly human phenotypes defective for factor VIII have been observed which probably result from mutation on at least three separate loci [10]: classic hemophilia due to a mutation at a gene locus on the $\mathrm{X}$-chromosome and expressed as a recessive trait; von Willebrand's disease, an autosomally transmitted trait which is clinically expressed in the heterozygote; and combined factor $\mathrm{V}$ and VIII deficiency, a rare autosomal phenotype expressed in the homozygote and characterized by a reduction of both factors. In addition, there appears to be an association between blood group and factor VIII levels; factor VIII levels are higher in Group A than in Group O individuals [65].

Classic hemophilia is controlled by a major gene on the $\mathrm{X}$-chromosome $[10$, 97]. It has been classified as a sex-linked recessive trait in that the bleeding deficiency almost always is expressed in males (with an X-Y sex chromosome pattern) while it is rarely expressed in females. The most celebrated case of hemophilia involved Queen Victoria and her descendants who controlled many of the governments of Europe; in this pedigree the disease was expressed in the males but was transmitted by the females [85]. A male who has hemophilia can transmit his affected $\mathrm{X}$-chromosome only to his daughter, who does not express the symptoms of hemophilia because she has received another normal X-chromosome from her mother. This daughter, however, is a carrier of the disease in that there is a $50 \%$ chance that any of her male offsprings will express the disease. In addition, women carriers of the mutant X-chromosome should have approximately $50 \%$ of the VIII coag that normal women have. Insofar as one can determine, because of the

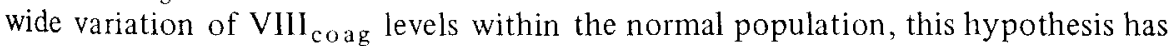
been found to be true $[72,93]$. Furthermore, the ratio of VIII ${ }_{\text {co ag }}$ to VIII ag levels in hemophilic carriers is $1 / 2$ that of normal and of most VWD individuals $[16,122]$. A woman can have classic hemophilia as a result of receiving a mutant X-chromosome from both her hemophilic father and her carrier mother; such cases are rare but they have been reported $[10,97]$. In other situations, women who were presumably hemophilic were shown to have a male sex chromatin pattern or XX-XO mosaicism.

The incidence of hemophilia has been estimated at 1 new hemophiliac in 10,000 to 30,000 live births, and this incidence appears to remain constant. Within a given hemophilic family, the level of factor VIII procoagulant activity and the severity of the disease remains constant in the affected males throughout their lives. Among unrelated hemophiliacs, the $\mathrm{VIII}_{\text {coag }}$ level has a range of 0 to slightly below normal. The difference in the expression of the disease is, therefore, believed to be affected by multiple alleles at the X-chromosome locus [10].

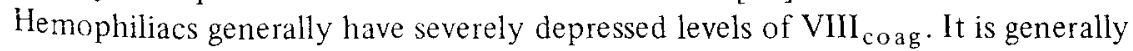
thought that the mutant gene does not allow synthesis of VIII coag protein. This appears to be the case with most hemophiliacs and they are classified as hemophilia A. However, as mentioned previously, in $6-15 \%$ of classic hemophiliacs there is 
synthesized a protein which is immunologically detectable with homologous antibodies but which is not functional [61]. From a biochemical viewpoint, there is a great difference between $\mathrm{A}^{-}$and $\mathrm{A}^{+}$individuals in terms of synthesis of VIII neut and mutation at the gene locus, in spite of the fact that the end result is the same in terms of the clinical manifestations. $\mathrm{A}^{+}$individuals probably arise as a result of a single mutation at the gene locus, whereas $\mathrm{A}^{-}$individuals would result from more than just a single mutation, perhaps gene repression or deletion, to mention two possibilities.

Factor VIII inheritance also appears to be controlled by at least one autosomal gene responsible for the von Willebrand's disease phenotype [10]. Although the original investigations into this bleeding disorder suggested that the inheritance of factor VIII was sex-linked dominant, because of the increased severity of the disease in females relative to males, the disease is now generally considered to be transmitted autosomally as a dominant character. There is confusion as to the expression of its dominant character because of the considerable variation in the clinical manifestations and in the laboratory assay values of factor VIII activities from person to person within a given family, and even within the same person throughout that person's lifetime. For these reasons, it is believed that there may be multiple alleles affecting the expression of this autosomal gene locus' synthesis of factor VIII. Furthermore, there may even be additional autosomal gene loci affecting this phenotype. The suggestion, that this may be so, is based upon the observations of Holmberg and Nilsson [53,54] of VWD individuals who had normal or elevated levels of $\mathrm{VIII}_{\mathrm{ag}}$. These authors suggested that these $\mathrm{CRM}^{+}$ individuals inherited an X-linked dominant trait. In contrast, most VWD individuals who are CRM inherit an autosomal dominant trait.

Over the last $30-40$ years, a number of theories have been proposed to account for the apparent discrepancies observed in the inheritance of factor VIII in hemophilia A and in von Willebrand's disease. Barrow and Graham [10] have summarized the essential features of these theories along with the key experimental results which led to the proposal of a new theory or which were discovered as a result of testing a new theory. All of these theories are speculative in that none of them answer all of the chemical and clinical observations encountered with factor VIII inheritance and synthesis. Several hypotheses have been proposed by Graham and associates; the essential features of each have been summarized by Owen, Bowie and Thompson [97] and by Ingram [65]. Graham's activator hypothesis suggests that a structural gene on the X-chromosome codes for the synthesis of an inactive precursor to factor VIII, whereas the autosomal gene synthesizes a substance which activates precursor-VIII. A mutation in the X-gene results in hemophilia $\mathrm{A}$; on the other hand, a mutation in the autosomal gene allows a nonfunctional precursor-VIII to be synthesized, a situation which results in VWD. Graham's regulatory hypothesis is based upon the Jacob and Monod model of bacterial protein synthesis. In this model, factor VIII is under the control of an $\mathrm{X}$-structural gene and an autosomal structural gene, each of which is under the control of another regulatory gene which acts by repression. The autosomal gene produces an effector which blocks the activity of X-regulatory gene on X-structural gene. Mutation in the X-gene results in hemophilia. Von Willebrand's disease would result from a mutation in the autosomal regulatory gene. This mutation would 
cause increased activity of repressor and thus depressed synthesis of autosomal effector substance; consequently, this reduced synthesis of autosomal effector allows X-regulatory gene to over-repress synthesis by X-structural gene. Graham's combining subunit hypothesis assumes that factor VIII is a multimer composed of peptide subunits, one under the control of the X-gene and the other under the control of paired genes on an autosome. Hemophilia could be explained by a mutation at X-locus; on the other hand, variations in VWD could be explained by a mutation at one or both genes of the autosomal locus. Once again, the theories are speculative and do not explain all of the experimental data. Much of the current research presumes that factor VIII is a polypeptide or a multimeric protein, but Barrow and Graham [10] stress that "too many genes are involved for factor VIII to be merely a peptide." This is consistent with the idea that the VIII $_{\text {ag }}$ is not VIII $_{\text {coag }}$ but that factor VII, as we previously have known it, may in fact be a complex of two tightly bound proteins, one a large multimeric carrier protein with VIII $_{\mathrm{ag}}$ and $\mathrm{VIII}_{\mathrm{VWF}}$ properties, and the other a rather small molecule with VIII $_{\text {coag }}$ properties of a very high specific activity.

\section{REFERENCES}

1. Abildgaard CF, J Vanderheiden, A Lindley, F Rickles: Studies of cross-reactivity of acquired factor VIII inhibitor activity in hemophilic plasma. Thromb Diath Haemorrh 18:354-363, 1967.

2. Addis T: The pathogenesis of hereditary hemophilia. J Pathol Bacteriol 15:427-452, 1911.

3. Aronson DL, JW Preiss, MW Mosesson: Molecular weights of factor VIII (AHF) and factor IX (PTC) by electron irradiation. Thromb Diath Haemorrh 8:270-275, 1962.

4. Barbui T, R Battista, E Dini: Relationship betwen ristocetin-induced platelet aggregation and factor VIII (activity and antigen) in von Willebrand's disease. Blut 29:260-264, 1974.

5. Barrow EM, S Amos, JB Graham: Certain biochemical properties of human AHF (factor VIII) separated from fibrinogen with manganous chloride and thrombin. J Lab Clin Med $68: 803-812,1966$.

6. Barrow EM, JB Graham: Kidney antihemophilic factor. Partial purification and some properties. Biochemistry 7:3917-3925, 1968.

7. Barrow EM, JB Graham: The dissociation of plasma antihemophilic factor by succinic anhydride. Fed Proc 28:746, 1969.

8. Barrow EM, JB Graham: Antihemophilic factor activity isolated from kidneys of normal and hemophilic dogs. Am J Physiol 220:1020-1024, 1971.

9. Barrow EM, JB Graham: Factor VIII (AHF) activity of small size produced by succinylating plasma. Am J Physiol 222:131-141, 1972.

10. Barrow EM, JB Graham: Blood coagulation factor VIII (Antihemophilic Factor): With comments on von Willebrand's disease and Christmas disease. Physiol Rev 54:23-74, 1974.

11. Barrow EM, JB Graham: Albumin and coagulation factor VIII (AHF). Am J Physiol 227:412-419, 1974 .

12. Barrow EM, CC Heindel, HR Roberts, JB Graham: Heterozygosity and homozygosity in von Willebrand's disease. Proc Soc Exp Biol Med 118:684-687, 1965.

13. Baugh R, J Brown, R Sargeant, C Houghie: Separation of human factor VIII activity from the von Willebrand's antigen and ristocetin platelet aggregating activity. Biochem Biophys Acta $371: 360-367,1974$.

14. Bennett B, WB Forman, OD Ratnoff: Studies on the nature of antihemophilic factor (factor VIII): Further evidence relating the AFH-like antigens in normal and hemophilic plasmas. J Clin Invest 52:2191-2197. 1973. 
15. Bennett B, OD Ratnoff: Studies of the response of patients with classical hemphilia to transfusions with concentrates of antihemophilic factor. J Clin Invest 51:2593-2596 1972.

16. Bennett B, OD Ratnoff: Detection of the carrier state for classic hemophilia. $\mathrm{N}$ Engl $J$ Med 288:342-345, 1973 .

17. Bennett B, OD Ratnoff, J Levin: Immunologic studies on von Willebrand's disease. J Clin Invest 51:2597-2601, 1972.

18. Biggs R, RG Macfarlane, KWE Denson, BJ Ash: Thrombin and the interaction of factors VIII and IX. Br J Haematol 11:276-295, 1965.

19. Biggs R, J Matthews: The treatment of haemorrhage in von Willebrand's disease and the blood level of factor VIII (AHG). Br J Haematol 9:203-214, 1963.

20. Bloom AL, JC Giddings, IR Peake: Low-molecular weight factor VIII. Lancet 1:661, 1973.

21. Bloom AL, JC Giddings, IR Peake: The presence and reactions of high and lower-molecular weight procoagulant factor VIII in the plasma of patients with von Willebrand's disease after treatment; significance for a structural hypothesis for factor VIII. Thromb Res 3:389-404, 1973 .

22. Bloom AL, JC Giddings, CJ Wilks: Factor VIII on the vascular intima: Possible importance in haemostasis and thrombosis. Nature [New Biol] 241:217-219, 1973.

23. Bouma BN, JJ Sixma, S DeGraff, Y Wiegerinck, JA Van Mourik, IA Mochtar: Factor VIII antigen and platelet retention in a glass bead column. Br J Haematol 25:645-656, 1973.

24. Bouma BN, JA Van Mourik, Y Wiegerinck, JJ Sixma, IA Mochtar: Immunological characterization of antihaemophilic factor A related antigen in haemophilia A. Scand $J$ Haematol 11:184-187, 1973.

25. Bouma BN, Y Wiegerinck, JJ Sixma, JA Van Mourik, IA Mochtar: Immunological characterization of purified antihaemophilic factor A (factor VIII) which corrects abnormal platelet retention in von Willebrand's disease. Nature [New Biol] 236:104-106, 1972.

26. Bowie EJW, P Didisheim, JH Thompson, Jr, CA Owen, Jr: The spectrum of von Willebrand's disease. Thromb Diath Haemorrh 18:40-56, 1967.

27. Brinkhous KM: A study on the clotting defect in hemophilia: the delayed formation of thrombin. Am J Med Sci 198:509-516, 1939.

28. Brinkhous KM: Antihemophilic factor (AHF) of plasma and plasma fractions. Proc 6th Congr Int Soc Hematol, Boston, 1958, p. 463.

29. Brown JE, RF Braugh, RB Sargeant, C Hougie: J Exp Med: in press. Cited in Davie EW, K Fujikawa: Basic mechanisms in blood coagulation. Annu Rev Biochem 44:799-829 (1975).

30. Cooper HA, RH Wagner: The defect in hemophilic and von Willebrand's disease plasmas studied by a recombination technique. J Clin Invest 54:1093-1099, 1974.

31. Cornu P, MG Larrieu, J Caen, J Bernard: Maladie de Willebrand: etude clinique, genetique et biologique. Nou Rev Fr Hematol 1:231-262, 1961.

32. Davie EW, K Fujikawa: Basic mechanisms in blood coagulation. Annu Rev Biochem 44:799-829, 1975.

33. De Gaetano G, MB Donati, J Vermylen: Evidence that human platelet aggregating activity in porcine plasma is a property of von Willebrand factor. Thromb Diath Haemorrh 32:549-553, 1974.

34. De Los Santos RP, LW Hoyer: Antihemophilic factor in tissues: Localization by immunofluorescence. Fed Proc 31:262, 1972.

35. Denson DWE, R Biggs, ME Haddon, R Borrett, K Cobb: Two types of haemophilia ( $A^{+}$and $\left.A^{-}\right)$: A study of 48 cases. Br J Haematol 17:163-171, 1969.

36. Donati MB, G De Gaetano, J Vermylen: Evidence that bovine factor VIII, not bovine fibrinogen, aggregates human platelets. Thromb Res 2:97-104, 1973.

37. Feinstein D, MNY Chong, CK Kasper, SE Rapaport: Hemophilia A: Polymorphism detectable by factor VIII antibody. Science 163:1071-1072, 1969.

38. Forbes CD, CRM Prentice: Aggregation of human platelets by purified porcine and bovine antihaemophilic factor. Nature [New Biol] 241:149-150, 1973.

39. Gobbi F: The fractionation properties of human factor VIII (anti-haemophilic factor) 
Thromb Diath Haemorrh 4:253-260, 1960.

40. Gordon NR, NR Shulman: The effect of clotting on structure and function of human factor VIII. Ann N Y Acad Sci 240:79-83, 1975.

41. Goudeman M, MS Foucaut, D Habay, A Parquet-Gernez: Les anti-coagulants circulants anti-facteur VIII au cours de l'hemophilie A. Nouv Rev Fr Hematol 3:703-722, 1963.

42. Graham JB, GIC Ingram (Chairmen): Preliminary report of the task force on nomenclature of factor VIII related activities. Int Soc Thrombosis and Haemostasis, Paris, 1975.

43. Graham JB, GD Penick, KM Brinkhous: Utilization of the anti-hemophilic factor during clotting of canine blood and plasma. Am J Physiol 164:710-715, 1951.

44. Gralnick HR, E Abrell, J Eagley: Immunologic studies of factor VIII in hemophilia A. Nature [New Biol] 230:16-17, 1971.

45. Gralnick HR, SL Marchesi, BS Coller: Theoretical approach to molecular biology of factor VIII heterogeneity of the molecule. Ann N Y Acad Sci 240:378-388, 1975.

46. Griggs TR, HA Cooper, WP Webster, RH Wagner, KM Brinkhous: Plasma aggregating factor (bovine) for human platelets: A marker for study of antihemophilic and von Willebrand factors. Proc Natl Acad Sci USA, 70:2814-2818, 1973.

47. Hagedorn B: Von Willebrand's disease. JAMA 216:991-995, 1971.

48.,Hershgold EJ: The subunit structure of human antihemophilic factor. Fed Proc 30:540, 1971.

49. Hershgold EJ: Recent advances in hemophilia. Discussion paper: Factor VIII. Ann N Y Acad Sci 240:70-73, 1975.

50. Hershgold EJ, AM Davison, ME Janszen: Isolation and some chemical properties of human factor VIII (antihemophilic factor). J Lab Clin Med 77:185-205, 1971.

51. Hershgold EJ, S Sprawls: Molecular properties of purified human, bovine and porcine antihemophilic globulins (AHG). Fed Proc 25:317, 1966.

52. Holmberg L: Recent advances in hemophilia. Discussion of Part I. Ann N Y Acad Sci 240:90, 1975.

53. Holmberg L, IM Nilsson: Genetic variants of von Willebrand's disease. Br Med J 3:317-320, 1972.

54. Holmberg L, IM Nilsson: Hemophilia A and von Willebrand's disease in a Swedish family. Scand Acta Paediat 61:517-525, 1972.

55. Holmberg L, N Rasovic, IM Nilsson: Von Willebrand's disease with normal factor VIII activity in a homozygote. Haemostasis 3:237-246, 1974.

56. Hougic C, DWE Denson, R Biggs: A study of the reaction product of factor VIII and factor IX by gel filtration. Thromb Diath Hemorrh 18:211-222, 1967.

57. Hougie C, RB Sargeant, JE Brown, RF Baugh: Evidence that factor VIII and the ristocetin aggregating factor $\left(\right.$ VII $_{\text {rist }}$ ) are separate molecular entities. Proc Soc Exp Biol Med 147:58-61, 1974.

58. Howard MA, BG Firkin: Ristocetin - a new tool in the investigation of platelet aggregation. Thromb Diath Haemorrh 26:362-369, 1971.

59. Howard MA, RJ Sawers, BG Firkin: Ristocetin: A means of differentiating von Willebrand's disease into two groups. Blood $41: 687-690,1973$.

60. Hoyer LW: Immunologic studies of AHF. III. Comparative binding properties of human and rabbit anti-AHF. Blood 39:481-489, 1972.

61. Hoyer LW, RT Breckenridge: Immunologic studies of antihemophilic factor (AHF, factor VIII): Cross-reacting material in a genetic variant of hemophilia A. Blood 32:962-971, 1968.

62. Hoyer LW, RT Breckenridge: Immunological studies of antihemophilic factor. II. Properties of CRM. Blood 35:809-820, 1970.

63. Hoyer LW, RP De Los Santos, JR Hoyer: Antihemophilic factor antigen. Localization in endothelial cells by immunofluorescent microscopy. J Clin Invest 52:2737-2744, 1973.

64. Ingram GIC: Blood-coagulation factor VIII: Genetics, physiological control and bioassay. Adv Clin Chem 8:189-236, 1965.

65. Ingram GIC: The genetics of clotting factor VIII. Med Lab Technol 28:76-80, 1971.

66. Jaffe EA: Synthesis of factor VIII antigen by cultured human endothelial cells. Ann N Y Acad Sci 240:62-69, 1975. 
67. Jaffe EA, LW Hoyer, RL Nachman: Synthesis of antihemophilic factor antigen by cultured human endothelial cells. $J$ Clin Invest 42:2757-2764, 1973.

68. Jaffe EA, LW Hoyer, RL Nachman: Synthesis of von Willebrand factor by cultured human endothelial cells. Proc Natl Acad Sci USA 71:1906-1909, 1974.

69. Johnson SA, J Rutsky, CL Schneider, WH Seegers: Activation of purified prothrombin with hemophilic plasma. Proc 4th Congr Int Soc Hematol 4:373-380, 1952.

70. Johnson SA, WH Seegers: Studies on the plasma defect in hemophilia. Rev Hématol 9:529-535, 1954.

71. Kass L, OD Ratnoff, MA Leon: Studies on the purification of antihemophilic factor (factor VIII). II. Separation of partially purified antihemophilic factor by gel filtration of plasma. J Clin Invest 48:957-962, 1969.

72. Kerr CB: Genetics of human blood coagulation. J Med Genet 2:254-303, 1965.

73. Lechner K: Inactive factor VIII in hemophilia A and von Willebrand's disease. Acta Haematol (Basel) 48:257-268, 1972.

74. Legaz ME, CM Heldebrant, EW Davie: Unpublished results. Cited in Davie EW, K Fujikawa: Basic mechanisms in blood coagulation. Annu Rev Biochem 44:799-829, 1975.

75. Legaz ME, G Schmer, RB Counts, EW Davie: Isolation and characterization of human factor VIII (antihemophilic factor). J Biol Chem 248:3946-3955, 1973.

76. Legaz ME, MJ Weinstein, CM Heldebrant, EW Davie: Isolation, subunit structure, and proteolytic modification of bovine factor VIII. Ann N Y Acad Sci 240:43-61, 1975.

77. Macfarlane RG, R Biggs, E Bidwell: Bovine antihaemophilic globulin in the treatment of haemophilia. Lancet 1:1316-1319, 1954.

78. Mammen EF: Biochemie und Kinetik des antihämophilen Globulins. Thromb Diath Haemorrh Suppl 14:89-105, 1964.

79. Mammen EF: Concentration of platelet cofactor I (factor VIII) from bovine serum. Thromb Diath Haemorrh 11:127-137, 1964.

80. Mammen EF: Physiology and biochemistry of blood coagulation. In: NU Bang, FK Beller, E Deutsch, EF Mammen (Eds): Thrombosis and Bleeding Disorders. Academic Press, New York, 1971, pp 1-56.

81. Mammen EF: This issue, pages 61-84.

82. Marchesi SL, NR Shulman, HR Gralnick: Studies on the purification and characterization of human factor VIII. J Clin Invest 51:2151-2161, 1972.

83. McKee PA: Purification and electrophoretic analysis of human antihemophilic factor (factor VIII). Fed Proc 29:647, 1970.

84. McKee PA, JC Andersen, ME Switzer: Molecular structural studies of human factor VIII. Ann N Y Acad Sci 240:8-33, 1975.

85. McKusick VA: The royal hemophilia. Sci Am 213:88-95, 1965.

86. Meyer D, MD Dreyfus, MJ Larrieu: Willebrand factor: Immunological and biological study. Pathol Biol Suppl (Paris) 21:66-71, 1973.

87. Meyer D, CSP Jenkins, MD Dreyfus, E Fressinaud, MJ Larrieu: Willebrand factor and ristocetin. II. Relationship between Willebrand factor, Willebrand antigen and factor VIII activity. Br J Haematol 28:579-599, 1974.

88. Meyer D, C Jenkins, M Dreyfus, MJ Larrieu: An experimental model for von Willebrand's disease. Nature 243:293-294, 1973.

89. Meyer D, CS Jenkins, M Dreyfus, MJ Larrieu: Willebrand-factor activity and antigen in von Willebrand's disease. Lancet 1:512-513, 1974.

90. Meyer D, MJ Larrieu: Factor VIII and IX variants. Relationship between haemophilia $B_{m}$ and haemophilia $\mathrm{B}^{+}$. Eur J Clin Invest 1:425-431, 1971.

91. Meyer D, JM Lavergne, MJ Larrieu, F Josso: Cross-reacting material in congenital factor VIII deficiencies (haemophilia $A$ and von Willebrand's disease). Thromb Res 1:183-196, 1972.

92. Michael SE, GW Tunnah: The purification of factor VIII (anti-haemophilia globulin). Br J Haematol 9:236-244, 1963.

93. Miller SP, J Siggerud: Abnormal blood coagulation in carriers of hemophilia. J Lab Clin Med 63:621-637, 1964.

94. Nilsson IM, B Blombäck, E Jorpes, B Blombäck, SA'Johansson: Von Willebrand's disease 
and its correction with human plasma fraction I-O. Acta Med Scand 159:179-188, 1957.

95. Olson ID, WJ Brockway, DN Rass, MA Magnuson, EJW Bowie: Evaluation of ristocetinWillebrand factor assay and ristocetin-induced platelet aggregation. Am J Clin Pathol $63: 210-218,1975$.

96. Osterud B, SI Rapaport: Synthesis of intrinsic factor X activator. Inhibition of the function of formed activator by antibodies to factor VIII and factor IX. Biochemistry 9:1854-1861, 1970.

97. Owen Jr CA, EJW Bowie, JW Thompson Jr: The diagnosis of bleeding disorders. Little, Brown, Boston, 1975, pp 183-207.

98. Owen WG, RH Wagner: Antihemophilic factor: Separation of an active fragment following dissociation by salts or detergents. Thromb Diath Haemorrh 27:502-515, 1972.

99. Patek AJ, FHC Taylor: Hemophilia. II: Some properties of a substance obtained from normal plasma effective in accelerating the clotting of hemophilic blood. J Clin Invest 16:113-124, 1937.

100. Pool JG, J Robinson: Assay of plasma antihaemophilic globulin (AHG). Br J Haematol $5: 17-23,1959$.

101. Rapaport SI, S Schiffman, MJ Patch, SB Ames: The importance of activation of antihemophilic globulin and proaccelerin by traces of thrombin in the generation of intrinsic prothrombinase activity. Blood $21: 221-236,1963$.

102. Ratnoff OD, B Bennett: Clues to the pathogenesis of von Willebrand's disease. $\mathrm{N}$ Engl J Med 289:1182-1 183, 1973.

103. Rick ME, LW Hoyer: Immunologie studies of antihemophilic factor (AHF, factor VIII). V. Immunologic properties of AHF subunits produced by salt dissociation. Blood 42:737-747, 1973.

104. Schmer G, EP Kirby, DC Teller, EW Davie: The isolation and characterization of bovine factor VIII (antihemophilic factor). J Biol Chem 247:2512-2521, 1972.

105. Shapiro GA, JC Anderson, SV Pizzo, PA McKee: The subunit structure of normal and hemophilic factor VIII. J Clin Invest 52:2198-2210, 1973.

106. Shapiro SS: The immunologic character of acquired inhibitors of antihemophilic globulin (factor VIII) and the kinetics of the interaction with factor VIII. J Clin Invest $46: 147-156,1967$.

107. Shapiro SS, M Hultin: Acquired inhibitors to the blood coagulation factors. Sem Thromb Hemost $1: 336-385,1975$.

108. Shinowara GY: Human antihemophilic globulin: Sources and properties. In: KM Brinkhous (Ed): The Hemophilias. University of North Carolina Press, Chapel Hill, NC, 1964, pp 87-99.

109. Stites DP, EJ Hershgold, JD Perlman, HH Fudenberg: Factor VIII detection by hemagglutination inhibition: Hemophilia $\mathrm{A}$ and von Willebrand's disease. Science 171:196-197, 1971.

110. Thelin GM, RH Wagner: Sedimentation of plasma antihemophilic factor. Arch Biochem Biophys 95:70-76, 1961.

111. Van Creveld S, HA Veder, CN Pascha, WF Kroeze: The separation of AHF from fibrinogen. Thromb Diath Haemorrh 3:572-577, 1959.

112. Van Mourik JA, BN Bouma, WT Labruyere, S De Graaf, IA Mochtar: Factor VIII, a series of homologous oligomers and a complex of two proteins. Thromb Res 4:155-164, 1974.

113. Van Mourik JA, WT Labruyere, BN Bouma, IA Mochtar: Structure and function of factor VIII. 4th Int Congr Thrombosis and Haemostasis, Vienna, Austria, 1973, p. 256.

114. Weiss HJ: Recent advances in hemophilia. Discussion of Part I. Ann N Y Acad Sci 240:87-89, 1975 .

115. Weiss HJ, LW Hoyer: Von Willebrand factor: Dissociation from antihemophilic factor procoagulant activity. Science 182:1149-1151, 1973.

116. Weiss HJ, LW Hoyer, FR Rickles, A Varma, J Rogers: Quantitative assay of plasma factor deficient in von Willebrand's disease that is necessary for platelet aggregation. Relationship to factor VIII procoagulant activity and antigen content. J Clin Invest 52:2708-2716, 1973.

117. Weiss HJ, S Kochwa: Molecular forms of antihaemophilic globulin in plasma, cryoprecipi- 
tate and after thrombin activation. Br J Haematol 18:89-100, 1970.

118. Weiss HJ, LL Phillips, W Rosner: Separation of subunits of antihemophilic factor (AHF) by agarose gel chromatography. Thromb Diath Haemorrh 27:212-219, 1972.

119. Weiss HJ, J Rogers, H Brand: Further studies on the von Willebrand factor (factor VIII)-ristocetin-induced platelet aggregation. Blood 40:939, 1972.

120. Weiss HJ, J Rogers, H Brand: Defective ristocetin-induced platelet aggregation in von Willebrand's disease and its correction by factor VIII. J Clin Invest 52:2697-2707, 1973.

121. Zimmerman TS, TS Eddington: Factor VIII coagulant activity and factor VIII-like antigen: independent molecular entities. J. Exp Med 138:1015-1020, 1973.

122. Zimmerman TS, OD Ratnoff, AS Littell: Detection of carriers of classic hemophilia using an immunologic assay for antihemophilic factor (factor VIII). J Clin Invest 50:255-258, 1971.

123. Zimmerman TS, OD Ratnoff, AE Powell: Immunologic differentiation of classic hemophilia (factor VIII deficiency) and von Willebrand's disease. J Clin Invest 50:244-254, 1971.

124. Vermylen J, G. DeGaetano, MB Donati, M Verstraete: Platelet-aggregating activity in neuraminidase-treated human cryoprecipitates: its correction with factor VIII related antigen. Br J Haematol 26:645-650, 1974.

125. Vermylen J, MB Donati, G DeGaetano, M Verstraete: Aggregation of human platelets by bovine or human factor VIIl. Role of carbohydrate side-chains. Nature 244:167-168, 1973. 